\title{
Pediatrik Ürolitiyazis Tedavisinde Beden Dışı Şok Dalga Litotripsi (ESWL) Sonuçlarımız: Tek Merkez Deneyimi
}

\section{The Results of Extracorporeal Shock Wave Lithotripsy (ESWL) in Pediatric Urolithiasis Treatment: A Single Center Experience}

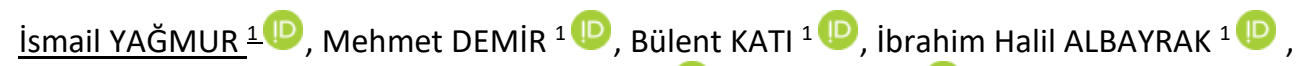 \\ Mehmet Kenan EROL ${ }^{2} \mathbb{D}$, Halil çifTçi ${ }^{1}$ (D) \\ ${ }^{1}$ Harran Üniversitesi Tıp Fakültesi, Üroloji AD, Şanlıurfa, Türkiye \\ ${ }^{2}$ Harran Üniversitesi Tıp Fakültesi Anesteziyoloji ve Reanimasyon AD, Şanlıurfa, Türkiye
}

Öz.

Amaç: Bu çalışmada amacımız ürolitiyazis nedeniyle ESWL uyguladığımız çocukların tedavi sonuçlarını değerlendirmektir.

Materyal ve metod: Ekim 2018-Ekim 2020 tarihleri arasında anestezi altında ESWL uygulanan çocukların kayıtları retrospektif olarak incelendi. Hastalar ESWL başarısına göre iki gruba ayrılarak yaş, cinsiyet, taş boyutu, taş lokalizasyonu, komplikasyonlar ve ek müdahaleler açısından karşılaştırıldı.

Bulgular: Çalışmaya dahil edilen 50 olgunun 34(\%68)'ü erkek, 16(\%32)'sı kız idi. Hastaların ortalama yaşı $8,8 \pm 5,0$ yıl idi. Taşların $29^{\prime}$ u sağ, $21^{\prime}$ i sol taraftaydı. Taşların 36 'sı böbrek, $14^{\prime}$ ü ise proksimal üreter yerleşimliydi. ESWL başarılı grupta taş boyutu ortalama $9.4 \pm 1.8 \mathrm{~mm}$, başarısız grupta ise $13.8 \pm 3.2 \mathrm{~mm}$ olarak saptandı $(\mathrm{p}<0.05) .10 \mathrm{~mm}$ 'nin altındaki taşlarda ESWL başarısı \%90 iken, $10 \mathrm{~mm}$ üzerindeki taşlarda \%56.7 olarak bulundu( $p<0,05)$. Toplam başarı \% 70 idi. Yaş, cinsiyet, taşların tarafı ve lokalizasyonları ile ESWL başarısı arasında anlamlı bir ilişki bulunmadı $(p>0,05)$. iki hastada taş yolu, 1 hastada üriner enfeksiyon ve 5 hastada geçici hematüri görüldü.

Sonuç: Ürolitiyazisli çocuklarda ESWL etkili ve güvenli bir tedavi yöntemidir. Taş boyutu başarıyı etkileyen önemli bir faktördür. Özellikle $\geq 10 \mathrm{~mm}$ taşlarda, seans başına maksimum yararlanmayı sağlayacak ve başarısız bir uygulamanın önüne geçebilecek öngörüyü ortaya çıkaracak çalışmalara ihtiyaç vardır.

Anahtar Kelimeler: Böbrek taşı, Pediatrik, Şok dalga, Litotripsi

\section{Abstract}

Background: Our aim is to evaluate the treatment results of children who underwent ESWL for urolithiasis

Materials and Methods: Records of children who underwent ESWL between October 2018 and October 2020 were retrospectively reviewed. The patients were divided into two groups according to success and compared in terms of age, gender, stone size, stone location, complications, and additional interventions.

Results: Of the 50 cases, $34(68 \%)$ were boys and $16(32 \%)$ were girls. The mean age was $8.8 \pm 5.0$ years. 36 of the stones were located in the kidney and 14 were in the proximal ureter. The average stone size was $9.4 \pm 1.8 \mathrm{~mm}$ in the successful ESWL group and $13.8 \pm 3.2 \mathrm{~mm}$ in the unsuccessful group $(p<0.05)$. While the success was $90 \%$ for stones less than $10 \mathrm{~mm}$, it was found to be $56.7 \%$ for stones over $10 \mathrm{~mm}(\mathrm{p}<0.05)$. Total success was $70 \%$. There was no significant correlation between age, gender, side and localization of stones and ESWL success ( $p>0.05)$.

Conclusion: ESWL is an effective and safe treatment method for children with urolithiasis. Stone size is an important factor affecting success. Especially for stones $\geq 10 \mathrm{~mm}$, there is a need for studies that will provide the maximum benefit per session and reveal the predictions that can prevent an unsuccessful application.

Key words: Urolithiasis, Pediatric, Shock wave, Lithotripsy 


\section{Giriş}

Üriner sistem taş hastalığı görülme sıklığı bölgelere göre farklılık göstermekle birlikte prevalansı \%2 \%20 arasında değişmektedir (1). Yüksek insidans ve prevalans oranları beslenme alışkanlıkları, sosyoekonomik koşullar, su tüketimi ve sıcak iklim koşulları ile ilişkilidir (2). Taş hastalığına sahip popülasyonun \% 2-3' ünü çocuklar oluşturmaktadır (3). Son dönemdeki çalışmalarda çocukluk çağı üriner sistem taş hastalığı sıklığının artmakta olduğu bildirilmektedir $(4,5)$. Bu durum özellikle bizimde içinde bulunduğumuz endemik taş kuşağındaki ülkelerde önemli problemleri bereberinde getirmektedir.

Çocuklarda böbrek taşlarının tedavisinde Beden dışı şok dalga litotripsisi (Extracorporeal Shock Wave Lithotripsy: ESWL), Üreterorenoskopi (URS), Retrograd Intrarenal Cerrahi (RIRC), Perkütan Nefrolitotomi (PNL), açık veya laparoskopik taş cerrahileri uygulanmaktadır. Son yıllardaki teknolojik gelişmeler, tedavi seçeneklerini açık cerrahilerden minimal invaziv cerrahilere yönelme şeklinde değiştirmiştir. Hatta ESWL'nin minimal invazivden ziyade non-invaziv bir yöntem olduğu da vurgulanmaktadır (5).

İlk kez 1980 yılında uygulamaya girdiği bilinen ESWL'nin, çocuklardaki kullanımına 1986 yılında Newman ve arkadaşları tarfından başlanmıştır (6). Yıllar içerisinde, çocuklardaki yüksek başarı oranlarının ve düşük komplikasyon oranlarının bildirilmesiyle birlikte ilk tercih tedaviler arasına girmiştir (7). Ürolitiyazisli çocuklarda etkin bir tedavi sonrasında bile yüksek rekürrens görülebilmesi nedeniyle, ESWL gibi minimal invaziv bir prosedürün ilk tercih olarak kullanılması akılcı bir yaklaşımdır.

Fakat ESWL başarısını etkileyen birçok faktör bulunmaktadır. Bunlar taşın boyutu, lokalizasyonu, bileşenleri, üriner sistem anatomisi, Vücut Kitle İndeksi (VKi), taş cilt mesafesi ve ESWL ekipmanı olarak bildirilmiştir (8-11). Ayaktan uygulanabilirliği, sedoaneljezinin yeterliliği, tekrarlanabilir oluşu ve diğer tedavi seçeneklerine kıyasla daha az invaziv oluşu önemli avantajlarıdır (12). Taşın distalinde konjenital (üreteropelvik veya üreterovezikal darlık gibi) veya başka bir taşa başı obstrüksiyon bulunması, üriner enfeksiyon ve kanama diyatezi gibi durumlarda uygulanması kontrendikedir (13).

Kliniğimizde yaklaşık 20 yıldır erişkin ESWL ve son iki yıldır da anestezi altında pediatrik ESWL yapılmaktadır. Bu çalışmada ürolitiyazis nedeniyle anestezi altında ESWL uyguladığımız çocukların tedavi sonuçlarını, komplikasyonlarını ve başarıyı etkileyen faktörleri araştırarak, yöntemin etkinlik ve güvenilirliğinin sunulması amaçlanmıştır.

\section{Materyal ve Metod}

Kliniğimizde Ekim 2018 - Ekim 2020 tarihleri arasında, böbrek veya proksimal üreter taşı nedeniyle ESWL tedavisi uygulanmış hastaların kayıtları retrospektif olarak incelendi. Anestezi ile ESWL tedavisi uygulanmış, 18 yaş altındaki ve en az 3 ay süreyle takibi bulunan çocuk olgular çalışmaya dahil edildi. Çalışma için Harran Üniversitesi Tıp Fakültesi Klinik Araştırmalar Etik Kurulu' ndan onay alındı (01.02.2021 tarih, HRU/21.03.22).

Tüm ESWL işlemleri bir elektrohidrolik litotriptör olan ELMED multimed klasik (Elmed Medikal Sistemleri, Ankara, Türkiye) cihazı ile supin pozisyonunda uygulandı. Odaklama işlemi için ultrasonik ve/veya floroskopik yöntem kullanıldı. Kliniğimizde pediatrik yaş grubunda $2 \mathrm{~cm}$ den küçük taşlara ESWL tedavisi önerilmektedir.

Hastalar anamnez, fizik muayene, serum üre-kreatinin ölçümleri, tam idrar tetkiki ve idrar kültürü ile değerlendirildi. Üriner enfeksiyon saptanan olgularda kültür-antibiyogram sonucuna uygun tedavi verildi ve işlem öncesi tüm hastalarda idrar sterilizasyonu sağlandı. Üriner sistem taş hastalığı tanısı Direk üriner sistem grafisi (DÜSG), Ultrasonografi (US) ve/veya düşük doz kontrastsız Bilgisayarlı Tomografi (BT) ile konuldu. İşlem öncesi ciddi hidronefrozu olan ve obstrüksiyon düşünülen olgulara JJ stent konuldu.

ESWL işlemi tüm olgulara sedoaneljezi altında uygulandı (midazolam 0,2-0,3 mg / kg, ketamin $1 \mathrm{mg} / \mathrm{kg}$, alfentanil 1-2 $\mu \mathrm{g}$ / kilogram). ESWL enerjisi 14-21 kilowatt (kV) arasında, 80/dk hızında ve 1800 vuru/seans şeklinde uygulandı. Tüm olgularda enerji düşük seviyeden başlayarak tedrici olarak arttırıldı. Tüm hastalar vital bulgular ve olası kardiyak aritmiler açısından monitorize edildi ve uygun sıvı replasmanı yapıldı. Çocuklar işlem sonrası 2 saat süreyle gözlem altında tutuldu.

Seanslar sonrasında birinci haftada, DÜSG ve USG ile taşlar fragmantasyon açısından değerlendirildi. Beş $\mathrm{mm}$ veya daha büyük fragman varlığında, seans aralarında en az 15 gün ve en fazla 3 seans olacak şekilde, tekrar ESWL uygulandı. Tüm hastalar son ESWL seansından 3 ay sonra değerlendirildi. Görüntülemede taş fragmanlarının olmaması ile üriner enfeksiyon ve obstrüksiyona neden olmayan klinik olarak önemsiz 4 mm' den küçük fragmanların 
varlığı başarı olarak kabul edildi (14). Seanslar sonrası taşların kırılmaması veya $5 \mathrm{~mm}$ ve üzerinde taş bulunması başarısızlık olarak kabul edildi.

Olgular ESWL başarılı ve başarısız olmak üzere 2 gruba ayrıldı. Gruplar yaş, cinsiyet, VKi, taş boyutu, lokalizasyonu, komplikasyonlar ve ek müdahale gerekliliği açısından karşılaştırıldı. Ayrıca hastalar taş boyutuna göre $<10 \mathrm{~mm}$ ve $\geq 10 \mathrm{~mm}$ şeklinde yine 2 gruba ayrılarak başarı oranları açısından karşılaştırıldı.

Istatistiksel analiz için SPSS 23.0 programı kullanıldı. Kategorik değişkenler için ki kare, sürekli değişkenler için student $t$ testi uygulandı ve $p<0,05$ anlamlı olarak kabul edildi.

\section{Bulgular}

Çalışmaya dahil edilen 50 olgunun 34 (\%68)' ü erkek, 16 (\%32)' sı kız idi. Hastaların ortalama yaşı 8,8 $\pm 5,0$ yıl idi. Taşların 29' u sağ, $21^{\prime}$ i sol taraftaydı. Taşların 36 tanesi böbrek, 14 tanesi ise proksimal üreter yerleşimliydi. Hasta ve taşların özellikleri Tablo $\mathbf{1}^{\prime}$ de özetlenmiştir.

Tablo 1. Hastalar ve Taşların Özellikleri

\begin{tabular}{|l|l|l|}
\hline & No & Oran \\
\hline Hasta/renal ünite sayısı & $50 / 50$ & $\% 100$ \\
\hline Ortalama yaş (yıl) & $8,8 \pm 5,0$ & \\
\hline Cinsiyet & & \\
$\quad$ Kız & 16 & $\% 32$ \\
Erkek & 34 & $\% 68$ \\
\hline Taş yönü & & \\
Sağ & 29 & $\% 58$ \\
Sol & 21 & $\% 42$ \\
\hline Ortalama taş boyutu (mm) & $10,7 \pm 3,0$ & \\
\hline Taş lokalizasyonu & & \\
Pelvis & 25 & $\% 50$ \\
Üst kaliks & 2 & $\% 4$ \\
Orta Kaliks & 5 & $\% 10$ \\
Alt Kaliks & 4 & $\% 8$ \\
Proksimal Üreter & 14 & $\% 28$ \\
\hline
\end{tabular}

Taş boyutu 20 hastada $<10 \mathrm{~mm}$ iken, 30 hastada $\geq 10$ $\mathrm{mm}$ idi. $10 \mathrm{~mm}^{\prime}$ nin altındaki taşlarda ESWL başarısı $\% 90$ iken, $10 \mathrm{~mm}$ ve üstündeki taşlarda $\% 56.7$ olarak bulundu. Aradaki fark istatistiksel anlamlı idi $(p<0,05)$ (Tablo 2).

Tablo 2. Taş boyutuna göre ESWL sonuçları

\begin{tabular}{|l|l|l|l|}
\hline Taş boyutu & Olgu sayısı & Taşsızlık Oranı & Ek müdahaleler \\
\hline$<10 \mathrm{~mm}$ & $\mathrm{n}=20$ & $\% 90$ & $\mathrm{n}=2(\% 6)$ \\
\hline$\geq 10 \mathrm{~mm}$ & $\mathrm{n}=30$ & $\% 56,7$ & $\mathrm{n}=14(\% 28)$ \\
\hline & $\mathrm{P}<0,05$ & $\mathrm{p}<0,05$ \\
\hline
\end{tabular}

ESWL başarılı grupta taş boyutu ortalama $9.4 \pm 1.8$ $\mathrm{mm}$ iken, başarısız grupta $13.8 \pm 3.2 \mathrm{~mm}$ olarak saptandı. Aradaki fark istatistiksel anlamlı olarak bulundu $(p<0.05)$. ESWL başarılı olan grupta yaş ortalaması $8.3 \pm 5.1$ yıl olup, başarısız grupta 10.1 \pm 4.9 idi. Aradaki fark istatistiksel anlamlı olarak saptanmadı $(p>0,05)$. Cinsiyet, VKi, taşların tarafı ve lokalizasyonu ile ESWL başarısı arasında anlamlı bir ilişki bulunamadı $(p>0,05)$ (Tablo 3 ).

Tablo 3. ESWL başarısı üzerine etkili faktörler

\begin{tabular}{|l|l|l|l|}
\hline & $\begin{array}{l}\text { ESWL başarılı } \\
\text { grup }\end{array}$ & $\begin{array}{l}\text { ESWL } \\
\text { başarısız grup }\end{array}$ & $\mathbf{P}$ \\
\hline Olgu sayısı (n) & $35(\% 70)$ & $15(\% 30)$ & \\
\hline Ortalama yaş (yıl) & $8,3 \pm 5,1$ & $10,1 \pm 4,9$ & $\mathrm{p}>0,05$ \\
\hline Cinsiyet (Kız, Erkek) & $11 \mathrm{~K}, 24 \mathrm{E}$ & $5 \mathrm{~K}, 10 \mathrm{E}$ & $\mathrm{p}>0,05$ \\
\hline $\begin{array}{l}\text { Ortalama taş } \\
\text { boyutu (mm) }\end{array}$ & $9,4 \pm 1,8$ & $13,8 \pm 3,2$ & $\mathrm{P}<0,05^{*}$ \\
\hline Taş lokalizasyonu & $\begin{array}{l}\text { Pelvis: } 18 \\
\text { Kaliks: 6 } \\
\text { Proksimal } \\
\text { üreter:11 }\end{array}$ & $\begin{array}{l}\text { Pelvis: 7 } \\
\text { Kaliks: 5 } \\
\text { Proksimal } \\
\text { üreter:3 }\end{array}$ & $\mathrm{p}>0,05$ \\
\hline Taş yönü seans & 14 sol, 21 sağ & 7 sol, 8 sağ & $\mathrm{p}>0,05$ \\
\hline $\begin{array}{l}\text { Ortalama } \\
\text { sayısı }\end{array}$ & 2,2 & \\
\hline $\begin{array}{l}\text { Ortalama vuru } \\
\text { sayısı/seans }\end{array}$ & 1800 & 1800 & \\
\hline $\begin{array}{l}\text { Ortalama Güç (kV: } \\
\text { kilowatt) }\end{array}$ & $15-17$ & $15-17$ & \\
\hline
\end{tabular}

Taş boyutu $<10 \mathrm{~mm}$ olan olguların sadece $2(\% 4)^{\prime}$ sinde, $\geq 10 \mathrm{~mm}$ olan olguların ise 12 (\%24)' sinde ilave prosedürler gerekli oldu. İşlem öncesi ciddi hidronefrozu olan 3 olguda işlem öncesi JJ stent konuldu. Uygulanan ek müdahaleler Tablo 4' de özetlenmiştir.

Tablo 4. Taş boyutuna göre gereken ek müdahaleler

\begin{tabular}{|c|c|}
\hline Taş boyutu & Işlemler ve olgu sayıları \\
\hline$<10 \mathrm{~mm}$ olanlar & $\begin{array}{l}\text { Üreterolitotomi }(n=1) \\
\text { Üreteroskopi }(n=1)\end{array}$ \\
\hline$\geq 10 \mathrm{~mm}$ olanlar & $\begin{array}{l}\text { Pre-ESWL JJ stent }(n=3) \\
\text { Perkütan Nefrolitotomi }(n=5) \\
\text { Retrograd İtrarenal Cerrahi + JJ stent }(n=5) \\
\text { Üreteroskopi }(n=2)\end{array}$ \\
\hline
\end{tabular}

Tüm seanslar değerlendirildiğinde genel başarı oranı $\% 70$ olarak bulundu. Komplikasyon olarak 2 hastada taş yolu, 1 hastada üriner enfeksiyon ve 5 hastada geçici hematüri görüldü.

\section{Tartışma}

Erişkinlerdeki ESWL tedavisinin başarı oranlarının ve komplikasyonlarının iyi bilinmesine rağmen, çocuklardaki ESWL tecrübesi sınırlıdır. Literatürde bildirilmiş birkaç tane geniş seri bulunmaktadır (10). Bizde kliniğimizde yaklaşık 20 yıldır erişkin ESWL uygulamamıza $(8,15)$ ve endemik taş bölgesinde bulunmamıza rağmen pediatrik ESWL son iki yıldır uygulanmaktadır. Çünkü 2016 yılına kadar hastanemizin 
ESWL ünitesi ile yatan hasta/ameliyathane kısmı farklı kampüslerde bulunmaktaydı. Bu nedenle taş kırma ünitemize anestezi hizmeti sağlanamadığından uzun bir süre pediatrik yaş grubuna ESWL hizmeti sunulamadı.

ESWL, $<20 \mathrm{~mm}$ böbrek taşları ve çoğu üreter taşları için daha az invaziv olması nedeniyle halen ilk seçenek tedavidir. Ancak $\geq 10 \mathrm{~mm}$ taşlarda, impakte taşlarda, kalsiyum oksalat monohidrat veya sistin taşlarında, taş cilt mesafesi fazla olanlarda, özellikle alt kaliks taşları için renal anatominin ve taş lokalizasyonunun uygun olmadığı olgularda başarı şansının düştüğü bilinmektedir $(13,15)$.

Literatürde taş boyutuna göre ESWL başarısı $<10$ mm taşlarda \%62.5 - 100 arasında, $\geq 10 \mathrm{~mm}$ taşlarda ise \%40 - 93.5 arasında değişmektedir (16) Bizim çaIışmamızda; <10mm taşlarda genel başarımız \%90 iken, $\geq 10 \mathrm{~mm}$ taşlarda \%56.7 olarak bulundu $(p<0,05)$. ESWL başarılı grupta taş boyutu ortalama $9.4 \pm 1.8 \mathrm{~mm}$ iken, başarısız grupta $13.8 \pm 3.2 \mathrm{~mm}$ olarak saptandı $(p<0.05)$. Her iki grupta da taş boyutu açısından başarı oranları literatürle uyumlu idi.

Çocuklardaki ESWL üzerine yapılan çalışmalara genel olarak bakıldığında tek seans sonrası taşsızlık oranı $\% 43.8$ - 82.4 arasında $(17,18)$, tekrarlayan seanslar sonrasında ise genel başarının \%70 ile \%90 arasına ulaştığı bildirilmiştir $(11,19)$. Bizim serimizde ilk seans sonrası başarı \%44 olup, tekrarlayan seanslarla \%70' e çıkmıştır. Literatürdeki oranlarla karşılaştıııldığında bizim başarı oranımız alt sınırdaki çalışmalarla benzerdir. Biz bu düşük oranın birkaç nedeni olabileceğini düşünüyoruz. Birincisi çalışmamızın anestezi ile ESWL uyguladığımız ilk 50 vakalık seriyi içermesi, ikincisi çalışmadaki hastalarımızın 30 (\%60)' unun $\geq 10 \mathrm{~mm}$ taşlara sahip olması, üçüncüsü ise ek müdahalede bulunulan hastalardaki taşların Hounsfield Ünitesi (HU) değerlerinin yüksek olmasıdır.

Üriner sistem taşlarının lokalizasyonu da başarı üzerine etkili faktörlerdendir. Renal pelvis, üst ve orta kaliks ile proksimal üreter taşlarında başarı yüksektir. Alt kaliks ve distal üreter taşlarında ise ESWL başarısı düşüktür $(16,20)$. Bizim serimizde taşların konumu ile başarı arasında bir ilişki bulunamamıştır. Biz bu durumu olgu sayımızın az olmasına ve taşların homojen dağılım göstermemesine bağlıyoruz. Literatürde proksimal üreter taşlarında ESWL'nin başarısı \%76 ile \%96 arasında değişmektedir $(18,21)$. Bizim serimizde proksimal üreter taşlarındaki başarı \%79(11/14) bulundu. Başarısız olan 3 olguda da HU değerleri > 900 olup, ayrıca URS de taşların 2' sinin impakte olduğu gözlendi. Hatta bu hastaların birinde endoskopik yöntemle başarı sağlanamaması nedeniyle üreterolitotomi prosedürü uygulandı.

Üriner sistem taşlarının sertliği, taşların bileşenlerine bağlı olarak değişmektedir. Sistin ve kalsiyum oksalat monohidrat taşların çok sert olmaları nedeniyle ESWL başarısı düşüktür (22). ESWL öncesi taş analizi yapılamadığından faydasız bir ESWL uygulanmasının önüne geçilememektedir. Fakat bilgisayarlı tomografide taşın HU değerine bakarak sertliği tahmin edilmekte ve ESWL başarısını öngörmede kullanılmaktadır. Massoud ve ark. yaptıkları bir çalışmada hastalarını HU değerlerine göre <500, $500-1000$ arası ve $>1000$ olarak 3 gruba ayırmışlar ve ESWL başarı oranlarını sırasıyla $\% 100, \% 95.7$ ve $\% 44.6$ olarak bildirmişlerdir (23). Fakat çocuklarda ESWL öncesi, yüksek radyasyon içermesi nedeniyle BT rutin olarak önerilmediğinden bu parametre ölçülememektedir. Bizim serimizde ESWL'nin başarız olduğu hastaların çoğunluğunda (11/15) ek müdahale öncesi çekilen $\mathrm{BT}^{\prime}$ de ortalama $\mathrm{HU}$ değeri $>1000$ olup literatürle uyumlu olarak yüksek idi.

Literatürde tekrarlayan ESWL, URS ve PNL gibi ek tedavi ihtiyacının \%4 -\%50 arasında olduğu bildirilmiştir. Yine ESWL öncesi JJ stent takılması gibi yardımcı yöntemlere de \% 4-12.5 arasında intiyaç duyulduğu bildirilmiştir (10). Bizim serimizde 3 (\%6) olguda işlem öncesi JJ uygulandı. Genel olarak 14 (\%28) hastada ise URS, PNL ve üreterolitotomi gibi gibi ek cerrahi müdahalelere ihtiyaç duyuldu. Bu hastaların büyük çoğunluğu $(n=12)$ taş boyutu $\geq 10 \mathrm{~mm}$ olan olgulardı.

Literatürde pediatrik ESWL komplikasyonlarının \%1,5 ile \%35 arasında değişmektedir (24). Bu komplikasyonların çoğunluğu hematüri, cilt ekimozu, renal kolik ve üriner enfeksiyon gibi hafif komplikasyonlardır $(10,16)$. Taş yolu oluşması gibi müdahale gerektiren komplikasyonlarda görülebilmektedir. Ancak nadiren subkapsüler, intrarenal, perirenal hematom, sepsis ve hemoptizi gibi önemli komplikasyonlar da görülebilmektedir (25). Bizim serimizdeki komplikasyonlara bakıldığında sadece 2 (\%4) olguda taş yolu oluşması nedeniyle endoskopik müdahale gerekti. Bir olguda üriner enfeksiyon, 5 olguda ise geçici hematüri görüldü. Toplam komplikasyon oranı \%16 (8/50) olarak hesaplandı ve bu oran da literatür ile uyumlu idi.

Çocuklarda taş hastalığının tekrarlama ihtimali yüksektir. Herhangi bir cerrahi tedavi ile taşlar tamamen çıkarılsa dahi 5 yıl içinde rekürrens ihtimali \%55 lere kadar çıkmaktadır (26). Bu nedenle minimal invaziv 
bir yöntem olan ve tekrarlayıcı şekilde kullanılabilen ESWL pediatrik yaş grubundaki ürolitiyazisin tedavisinde önemli bir yer tutmaktadır.

Çalışmamızın kısıtlamaları retrospektif oluşu, yaş dağılımının heterojen oluşu, kalisiyel anatomi ve infundibulopelvik açı gibi faktörlerin değerlendirilememesi ile taş bileşenin bilinmemesidir.

Sonuç:

ESWL minimal invaziv ve tekrarlanabilir özelliği sayesinde etkili ve güvenli bir tedavi yöntemidir. Taş boyutu başarıyı etkileyen önemli bir faktördür. Özellikle $\geq 10 \mathrm{~mm}$ taşlarda seans başına maksimum yararlanmayı sağlayacak ve başarısız bir ESWL uygulamasının önüne geçebilecek öngörüyü ortaya çıkaracak çalışmalara intiyaç vardır. Bu sayede çoğu merkezde başarı oranlarının yüksek ve standart hale gelebileceğini düşünüyoruz.

Etik onam: Çalışma için Harran Üniversitesi Tıp Fakültesi Klinik Araştırmalar Etik Kurulu'ndan etik onam alındı (01.02.2021 tarihli, HRU/21.03.22).

\section{Yazar Katkıları:}

Konsept: i.Y., B.K.

Literatür Tarama i.Y., M.D., B.K.

Tasarımı: I.Y., H.Ç.

Veri toplama: I.Y., i.H.A., M.K.E.

Veri analizi ve yorumlama: I.Y., M.D., H.Ç.

Makale yazımı: I.Y., M.K.E.

içeriğin eleştirel incelenmesi: H.Ç., B.K.

Çıkar Çatışması: Yazarlar çıkar çatışması beyan etmemişlerdir. Finansal Destek: Yazarlar finansal destek beyan etmemişlerdir.

Teşekkür: Kliniğimizin ESWL ünitesinde uzun yıllardır görev yapan Mahmut Gazi ŞAŞMAZ'a verdiği hizmetlerden dolayı teşekkürlerimizi sunuyoruz.

\section{Kaynaklar}

1. Muslumanoglu AY, Binbay M, Yuruk E, Akman T, Tepeler A, Esen $T$, et al. Updated epidemiologic study of urolithiasis in Turkey. I: Changing characteristics of urolithiasis. Urological Research. 2011; 39(4):309-314.

2. Ansari MS, Gupta NP, Hemal AK, Dogra PN, Seth A, Aron M, et al. Spectrum of stone composition: structural analysis of 1050 upper urinary tract calculi from northern India. Int J Urol. 2005; 12(1):12-6.

3. Sharma AP, Filler G. Epidemiology of pediatric urolithiasis. Indian J Urol. 2010; 26(4):516-22.

4. Clayton DB, Pope JC. The increasing pediatric stone disease problem. Ther Adv Urol. 2011; 3(1):3-12.

5. Destro F, Selvaggio GGO, Lima M, Riccipetitoni G, Klersy C, Di Salvo N, et al. Minimally Invasive Approaches in Pediatric Urolithiasis. The Experience of Two Italian Centers of Pediatric Surgery. Front Pediatr. 2020; 24: 8:377.

6. Newman DM, Coury T, Lingeman JE, Mertz JH, Mosbaugh PG, Steele RE, et al. Extracorporeal shock wave lithotripsy experience in children. J Urol. 1986; 136(1 Pt 2):238-40.

7. Özçakır E, Özçakır L, Kaçar M, Altındağ T, Erdoğan H, Durmaz
O, et al. Çocuklarda üriner sistem taş hastalığı tedavisinde ESWL deneyimlerimiz. Çocuk Cerrahisi Dergisi. 2010; 24:12-17.

8. Demir M, Dere O, Yağmur I, Katı B, Pelit ES, Albayrak iH, et al. Usability of shear wave elastography to predict the success of extracorporeal shock-wave lithotripsy: prospective pilot study. Urolithiasis. 2020; 26:1-6.

9. Lee HY, Yang YH, Lee YL, Shen JT, Jang MY, Shih PM, et al. Noncontrast computed tomography factors that predict the renal stone outcome after shock wave lithotripsy. Clin Imaging. 2015; 39(5):845-50.

10. Grivas N, Thomas K, Drake T, Donaldson J, Neisius A, Petřík $A$, et al. Imaging modalities and treatment of paediatric upper tract urolithiasis: A systematic review and update on behalf of the EAU urolithiasis guidelines panel. J Pediatr Urol. 2020; 16(5):612-624.

11. Dogan HS, Altan M, Citamak B, Bozaci AC, Karabulut E, Tekgul S. A new nomogram for prediction of outcome of pediatric shock-wave lithotripsy. J Pediatr Urol. 2015; 11. 84.e1-6.

12. Osman Ergün. Beden Dışı Şok Dalga ile Taş Kırma Tedavisinin Başarı ve Sonucu Üzerine Etkili Faktörler. Süleyman Demirel Üniversitesi Sağlık Bilimleri Dergisi. 2018; 9.2: 54-57.

13. Gültekin MH, Türegün FA, Önal B. ESWL: Henüz Ölmedi, Başarı Oranlarını Arttırabiliriz? Endoüroloji Bülteni. 2015; 8:72-74. 14. Shouman AM, Ghoneim IA, ElShenoufy A, Ziada AM. Safety of ungated shockwave lithotripsy in pediatric patients. J Pediatr Urol. 2009; 5(2):119-21.

15. Kati B, Pelit ES, Yagmur I, Sagir S, Ciftci H, Yeni E. Effects of the distance between renal calculi and skin and the body mass index on the success of ESWL among renal calculi patients. JOJ Urol Nephrol. 2017; 3, 3.

16. Yılmaz Aksoy, Turgut Yapanoğlu. Çocukluk Taş Hastalığında Extracorporeal Shock Wave Lıthotrıpsy: Hala Yaşıyor ve Çok Etkili. Endoüroloji Bülteni. 2016; 9:10-13.

17. El-Sheemy MS, Daw K, Habib E, Aboulela W, Fathy H, Shouman AM, et al. Lower calyceal and renal pelvic stones in preschool children: a comparative study of minipercutaneous nephrolithotomy versus extracorporeal shockwave lithotripsy. Int J Urol. 2016; 23:564e70.

18. Badawy AA, Saleem MD, Abolyosr A, Aldahshoury M, Elbadry MS, Abdalla MA, et al. Extracorporeal shock wave lithotripsy as first line treatment for urinary tract stones in children: outcome of 500 cases. Int Urol Nephrol. 2012; 44: 661e6.

19. Alsagheer G, Abdel-Kader MS, Hasan AM, Mahmoud O, Mohamed $O$, Fathi $A$, et al. Extracorporeal shock wave lithotripsy (ESWL) monotherapy in children: predictors of successful outcome. J Pediatr Urol. 2017; 13. 515.e1-515.e5.

20. Kızılay F, Özdemir T, Turna B, Karaca N, Şimşir A, Alper I, et al. Factors affecting the success of pediatric extracorporeal shock wave lithotripsy therapy: 26-year experience at a single institution. Turk J Pediatr. 2020; 62(1):68-79.

21. Lu J, Sun X, He L, Wang Y. Efficacy of extracorporeal shock wave lithotripsy for ureteral stones in children. Pediatr Surg Int. 2009; 25(12):1109-12.

22. Dretler SP. Stone fragility: a new therapeutic distinction. J Urol. 1988; 139(5):1124-7.

23. Massoud AM, Abdelbary AM, Al-Dessoukey AA, Moussa AS, Zayed AS, Mahmmoud O. The success of extracorporeal shockwave lithotripsy based on the stone-attenuation value from non-contrast computed tomography. Arab J Urol. 2014; 12(2):155-61.

24. Silay MS, Ellison JS, Tailly T, Caione P. Update on Urinary Sto- 
nes in Children: Current and Future Concepts in Surgical Treatment and Shockwave Lithotripsy. Eur Urol Focus. 2017; 3(23):164-171.

25. D'Addessi A, Bongiovanni L, Sasso F, Gulino G, Falabella R, Bassi P. Extracorporeal shockwave lithotripsy in pediatrics. J Endourol. 2008; 22(1):1-12.

26. Lao M, Kogan BA, White MD, Feustel PJ. High recurrence rate at 5-year followup in children after upper urinary tract stone surgery. J Urol. 2014; 191(2):440-4. 